\title{
Role of local treatment including radiotherapy in Barcelona Clinic of Liver Cancer stage C patients: a nationwide cohort analysis in South Korea
}

This article was published in the following Dove Medical Press journal: Cancer Management and Research

\author{
Jeongshim Lee ${ }^{1,2}$ \\ Won Sup Yoon ${ }^{3}$ \\ Woong Sub Koom' \\ Chai Hong Rim ${ }^{3}$ \\ 'Department of Radiation Oncology, \\ Yonsei University College of Medicine, \\ Seoul, Republic of Korea; ${ }^{2}$ Department \\ of Radiation Oncology, Inha University \\ Hospital, Incheon, Republic of Korea; \\ ${ }^{3}$ Department of Radiation Oncology, \\ Ansan Hospital, Korea University \\ Medical College, Ansan, Republic of \\ Korea
}

On behalf of the Korean Liver Cancer Study Group
Correspondence: Chai Hong Rim Department of Radiation Oncology, Ansan Hospital, Korea University, 123 Jeokgeum-ro, Danwon-gu, Ansan, Gyeonggi-do 15355, Republic of Korea Tel/fax +82 3I 4126850

Email crusion3@naver.com
Purpose: Sorafenib is recommended as the standard treatment for hepatocellular carcinoma (HCC) of Barcelona Clinic of Liver Cancer stage C (BCLC C). However, local treatment including radiation therapy (LRT) is also widely administered in practice. The aim of our study was to define the role of LRT among BCLC C patients.

Patients and methods: Of the patients with HCC enrolled the Korean Central Cancer Registry from 2008 to 2014, the Korean Liver Cancer Study Group randomly extracted 10,580 patient data from $\sim 50$ hospitals nationwide. Among them, 3,401 patients were categorized to have BCLC C HCC. Among them, patients with information on initial treatments, defined as the first and secondary treatment within 60 days after the first treatment, were selected and classified into three initial treatment groups: LRT, sorafenib, and no treatment.

Results: Among 3,401 BCLC C HCC patients, 1,486 were included in the study and the remaining patients were excluded as they did not meet the criteria (eg, underwent local treatments without radiotherapy [RT] or received chemotherapy other than sorafenib). Of these, 266 were assigned to LRT (17.9\%), 316 to sorafenib (21.3\%), and 904 to no treatment group $(60.8 \%)$. Median survival time of the sorafenib group was shorter than that of the LRT group (3.8 vs 7.6 months, $P<0.001)$. In multivariable analysis, sorafenib group showed significantly higher risk related to mortality compared to LRT group, not only among all patients (HR: $1.50,95 \% \mathrm{CI}$ : $1.23-1.84)$ but also between subgroup cohorts with portal invasions (1.55, 1.23-1.84), with lymph node metastases $(2.42,1.53-3.83)$, without distant metastases $(1.43,1.10-1.87)$, and with distant metastases $(1.57,1.13-2.19)$. Additionally, no treatment group showed the worst survival among the three treatment groups not only in all patients, but also in all subgroups of patients $(P<0.001$ in all).

Conclusion: LRT as an initial treatment showed survival benefit as compared to sorafenib in HCC patients of BCLC C.

Keywords: hepatocellular carcinoma, BCLC C, sorafenib, radiation therapy, survival

\section{Introduction}

Hepatocellular carcinoma (HCC) is one of the common cancers worldwide and the most common primary liver malignancy. ${ }^{1}$ Unfortunately, $>50 \%$ of HCC cases have advanced stage of the disease and show a dismal prognosis with median overall survival (OS) of below 12 months. ${ }^{2}$ Generally, cancer staging systems provide guidelines for tumor assessment, severity, treatment, and prognosis. Among various staging systems for $\mathrm{HCC}$, the Barcelona Clinic of Liver Cancer (BCLC) classification, categorizing HCC as A (early), B (intermediate), and C (advanced) stages, is helpful by providing both prognostic prediction and treatment allocation, and therefore, it has been most widely 
used. ${ }^{3,4}$ In BCLC staging system, BCLC stage C (BCLC C) encompasses heterogeneous populations, including patients with suboptimal performance status, portal invasion (PI), or extrahepatic nodal/distant spread among patients with preserved liver function of Child-Pugh Class A or B. ${ }^{5}$

Currently, for BCLC C, sorafenib is the only proven firstline standard treatment according to two landmark randomized trials, Sorafenib HCC Assessment Randomized Protocol Trial (SHARP) ${ }^{6}$ and the Asia-Pacific Study, ${ }^{7}$ which reported median survival of 10.7 and 6.5 months, respectively, among advanced HCC patients. Although modest survival benefits are achieved, locoregional treatments are commonly used in clinic as significant tumor responses are rarely observed with sorafenib. Radiotherapy (RT) has been used emergently for BCLC C HCCs thanks to technological advances, and it helps to achieve significant tumor response $(\sim 60 \%)$ and sustained local control. ${ }^{8}$ Furthermore, recently, a randomized trial demonstrated that, for advanced $\mathrm{HCC}$ with macroscopic vascular invasion, first-line treatment with combined treatment of transarterial chemoembolization (TACE) plus RT provided an increased progression-free survival and OS as compared with sorafenib. ${ }^{9}$

$\mathrm{HCC}$ is the second leading cause of cancer death in the Republic of Korea, with an incidence of 31 per 100,000 population in the year $2015 .{ }^{10}$ In clinical practice, RT has been commonly used as an initial treatment for HCC, not only as a palliative treatment, but also for treating locally advanced tumors, and $22 \%$ of all HCC patients underwent RT in 2014. ${ }^{11,12}$ Hence, integrating clinical experiences of treating $\mathrm{HCC}$ in the Republic of Korea might be helpful to identify the role of local treatment including RT (LRT) as an initial treatment. Therefore, we conducted a nationwide population-based, retrospective cohort study to investigate the role of LRT among BCLC C patients in the real world, focusing on the oncologic outcomes in comparison with sorafenib.

\section{Patients and methods Database source}

The Korean Ministry of Health and Welfare has initiated a project called Korean Central Cancer Registry (KCCR) since 1980. The Korean Liver Cancer Study Group (KLCSG) and the National Cancer Center have extracted HCC patients' records from the $\mathrm{KCCR}$ to settle the mother population, which have been assigned codes of C22.0 according to the ICD-10.

KLCSG performed projects three times (in the years 2008-2010, 2011-2012, and 2013-2014), and 47, 50, and 51 hospitals in the Republic of Korea were randomly selected among all hospitals nationwide which registered HCC patients in the KCCR. At least one hospital was selected from all 16 administrative districts in the Republic of Korea, and the probability proportional extraction method, which is more likely to select hospitals with a large number of registered patients, was used. Through three projects, the records of 10,580 patients who were initially diagnosed as HCC between 2008 and 2014 were sampled. This cohort represented $11.7 \%$ of all $\mathrm{HCC}$ patients registered in KCCR during the corresponding period.

Data on dates and causes of mortalities were obtained from the Korean Statistical Information Service. The date of the first diagnosis of HCC was provided in the data of the KCCR. Most recent follow-up date for survivors was December 31, 2016, and for those who were deceased, it was the time of death.

Our study design is schematically summarized in Figure 1.

\section{Study cohort}

Of the 10,580 HCC patients, 3,401 patients (32.1\%) were categorized as BCLC C. Among them, portal vein invasion was found in 1,980 patients (58.2\%), lymph node metastasis (LNM) in 641 patients (18.8\%), and distant metastasis (DM) in 892 patients $(26.2 \%)$. The BCLC C patients who were treated with sorafenib, LRT, and no treatment as the "initial treatments" (the first treatment and the second treatment within 60 days after the first treatment) were included in the study. The term initial treatments was defined to exclude treatments for recurrence or progressed disease, but to encompass treatments for the initial disease at the primary clinical decision. The term "no treatment" denotes that the patient did not receive any of the treatments including surgery, radiofrequency ablation of ethanol injection, transarterial therapies, and chemotherapies including sorafenib at the initial decision. RT refers to external RT only, not selective internal RT or transarterial radioembolization using radioisotopes. LRT is defined as RT that is included as an initial treatment modality as first or second treatment. We used the term LRT rather than RT, as many RTs were performed in concordance with TACE and both modalities have the same treatment purpose as locoregional treatment. The patients were grouped according to their initial treatment modalities performed. Clinical factors including gender, age, hepatitis B, hepatitis C, Eastern Cooperative Oncology Group performance score, tumor size, PI, LNM, DM, and Child-Pugh score were analyzed. 


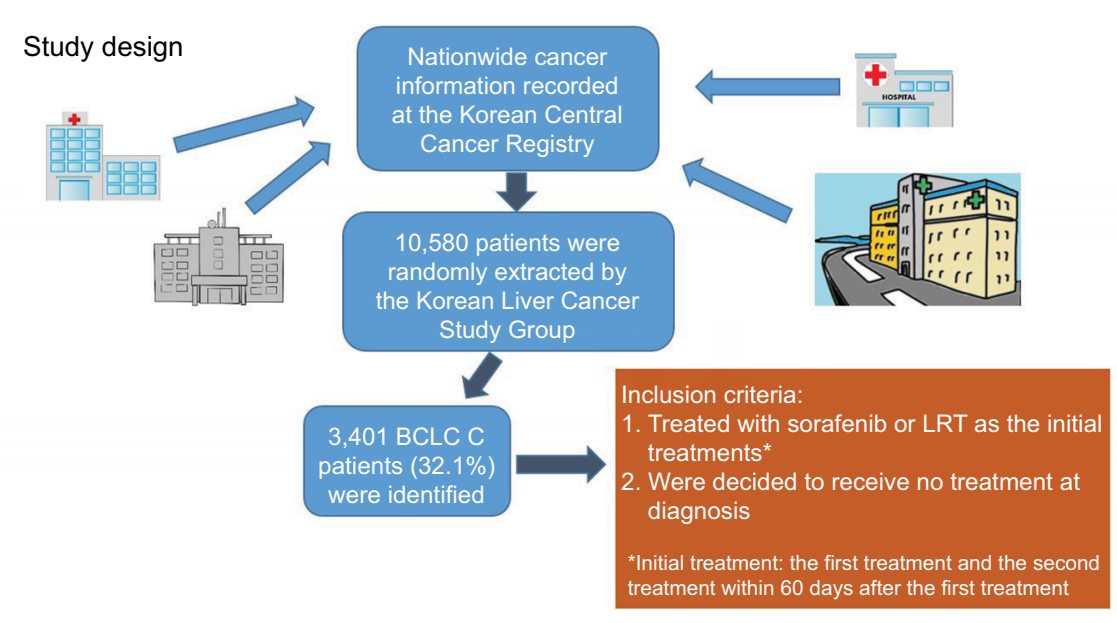

Figure I Schematic summary of the study design.

Abbreviations: BCLC C, Barcelona Clinic of Liver Cancer stage C; LRT, local treatment including radiotherapy.

\section{Outcome assessments and statistical analysis}

The primary endpoint was OS. Also, we investigated relevant clinical variables related to OS. Chi-squared test was used for comparison of categorical variables among treatment groups, while ANOVA was used for comparison of continuous variables. Survival analyses were performed using Kaplan-Meier method, and log-rank test was used for intergroup comparison. For multivariate analysis, Cox proportional hazards model was used. All the statistical analyses were performed using SPSS v20.0 (IBM Corporation, Armonk, NY, USA).

\section{Ethical consideration}

The data source of the present study is a public open data without personal identification information from KCCR, and the institutional review board approval was waived. Otherwise, we recognized and adhered to the World Medical Association Declaration of Helsinki.

\section{Results}

\section{Patient characteristics}

Among 3,401 HCC patients of BCLC C diagnosed from 2008 to 2014 , a total of 1,486 patients were included as they underwent LRT, sorafenib, or no treatment as the initial treatment; the remaining patients were excluded as they did not meet the inclusion criteria (eg, underwent local treatments without RT, such as TACE, radiofrequency ablation, or surgery, or chemotherapy other than sorafenib). Of them, 266 (17.9\%), $316(21.3 \%)$, and $904(60.8 \%)$ were categorized as LRT, sorafenib, and no treatment group, respectively. Twenty-one patients who received both RT and sorafenib as the initial treatment were categorized in the LRT group.
Between LRT and sorafenib groups, two clinical factors out of eight including tumor size and DM were significantly different. Sorafenib group had more patients with the largest tumor size of $>10 \mathrm{~cm}(56.0 \%$ vs $44.0 \%, P=0.006)$ and more patients with DM $(50.6 \%$ vs $34.2 \%, P<0.001)$. A nonsignificant trend of higher Child-Pugh score in the sorafenib group compared to LRT group (mean value: 6.24 [95\% CI: 6.09-6.40] vs 5.94 [95\% CI: 5.79-6.08], $P=0.059$ ) was found. TACE was combined as the initial treatment in $47.7 \%$ of the LRT group patients and $17.7 \%$ of the sorafenib group patients $(P<0.001)$. In the LRT group, treatments other than RT or TACE which were performed as the initial treatments were 2 cases of surgical resection $(0.7 \%), 1$ case of liver transplantation $(0.4 \%), 28$ cases of chemotherapy other than sorafenib (10.5\%), and 5 cases of chemotherapy (1.8\%) with unreported regimen. In the sorafenib group, treatments other than sorafenib or TACE which were performed as the initial treatment were three cases of surgical resection $(0.9 \%)$, one case of radiofrequency ablation $(0.3 \%)$, and five cases of chemotherapy other than sorafenib (1.6\%). The characteristics of the patients categorized in the initial treatments groups are summarized in Table 1.

\section{Survival analyses}

Results of univariate analyses related to survival according to treatment groups for all patients and each subgroup of patients by various factors are shown in Table 2 and Figure 2 . Median follow-up time for survivors was 44.5 months. In univariate analysis, in the whole population, RT group showed superior OS at 12 months compared to sorafenib group (36.5\% vs $17.7 \%, P<0.001$; Figure $2 \mathrm{~A}$ ). Median OS was 7.6 months (range: $6.1-9.1$ ) in the LRT group and 3.8 
Table I Patients' characteristics according to treatment groups

\begin{tabular}{|c|c|c|c|c|c|}
\hline \multirow[t]{2}{*}{ Variables } & \multirow{2}{*}{$\begin{array}{l}\text { LRT } \\
n=266\end{array}$} & \multirow{2}{*}{$\begin{array}{l}\text { Sorafenib } \\
n=316\end{array}$} & \multirow{2}{*}{$\begin{array}{l}\text { No treatment } \\
\mathrm{n}=904\end{array}$} & \multicolumn{2}{|l|}{$P$-value } \\
\hline & & & & All groups & RT vs sorafenib \\
\hline \multicolumn{6}{|l|}{ Clinical factors } \\
\hline \multicolumn{6}{|l|}{ Age } \\
\hline Mean $(95 \% \mathrm{Cl})$ & $55.1(53.8-56.5)$ & $57.4(56.1-58.7)$ & $62.1(61.3-63.0)$ & $<0.001$ & 0.068 \\
\hline Gender & & & & 0.231 & 0.389 \\
\hline Male & $222(83.5 \%)$ & $27 \mid(86.0 \%)$ & 740 (81.9\%) & & \\
\hline Female & 44 (16.5\%) & $44(14.0 \%)$ & $164(18.1 \%)$ & & \\
\hline Hepatitis B & & & & $<0.001$ & 0.722 \\
\hline Yes & 191 (73.2\%) & $222(71.8 \%)$ & $373(42.6 \%)$ & & \\
\hline No & $70(26.8 \%)$ & $87(28.2 \%)$ & $502(57.4 \%)$ & & \\
\hline Hepatitis C & & & & 0.036 & 0.132 \\
\hline Yes & $25(10.0 \%)$ & $19(6.4 \%)$ & $100(11.7 \%)$ & & \\
\hline No & $226(90.0 \%)$ & $276(93.6 \%)$ & $753(88.3 \%)$ & & \\
\hline ECOG & & & & 0.001 & 0.297 \\
\hline 0 & $119(57.5 \%)$ & $126(50.2 \%)$ & $296(48.2 \%)$ & & \\
\hline 1 & 75 (36.2\%) & $107(42.6 \%)$ & $226(36.8 \%)$ & & \\
\hline 2 & $13(6.3 \%)$ & $18(7.2 \%)$ & $92(15.0 \%)$ & & \\
\hline Tumor size, $\mathrm{cm}$ & & & & 0.022 & 0.006 \\
\hline$>10$ & $117(44.0 \%)$ & 175 (55.4\%) & 445 (49.2\%) & & \\
\hline$\leq 10$ & 149 (56.0\%) & I4I (44.6\%) & 459 (50.8\%) & & \\
\hline Portal invasion & & & & 0.029 & 0.784 \\
\hline Yes & $196(73.7 \%)$ & $236(74.7 \%)$ & $613(67.8 \%)$ & & \\
\hline No & $70(26.3 \%)$ & $80(25.3 \%)$ & 291 (32.2\%) & & \\
\hline $\mathrm{LN}$ metastasis & & & & 0.289 & 0.343 \\
\hline Yes & $56(21.1 \%)$ & 77 (24.4\%) & $233(25.8 \%)$ & & \\
\hline No & $210(78.9 \%)$ & 239 (75.6\%) & 671 (74.2\%) & & \\
\hline Distant metastasis & & & & $<0.001$ & $<0.001$ \\
\hline Yes & 91 (34.2\%) & $160(50.6 \%)$ & $323(35.7 \%)$ & & \\
\hline No & $175(65.8 \%)$ & $156(49.4 \%)$ & $581(64.3 \%)$ & & \\
\hline \multicolumn{6}{|l|}{ Child-Pugh score } \\
\hline Mean $(95 \% \mathrm{Cl})$ & $5.94(5.79-6.08)$ & $6.24(6.09-6.40)$ & $6.68(6.57-6.79)$ & $<0.001$ & 0.059 \\
\hline \multicolumn{6}{|c|}{ Treatment factors } \\
\hline Combined TACE & & & & & $<0.001$ \\
\hline Yes & I 27 (47.7\%) & $56(17.7 \%)$ & & & \\
\hline No & $139(52.3 \%)$ & $260(82.3 \%)$ & & & \\
\hline
\end{tabular}

Abbreviations: ECOG, Eastern Cooperative Oncology Group performance score; LN, lymph node; LRT, locoregional treatment including radiotherapy; RT, radiotherapy; TACE, transarterial chemoembolization.

months (range: $3.5-4.1)$ in the sorafenib group $(P<0.001)$. No treatment group showed the worst median and 12-month OS rate for all patients (2.3 months and $15.2 \%$, respectively). Median OS of 21 patients who underwent both RT and sorafenib was 6.6 months.

We performed the subgroup analysis by various variables such as with PI, with LNM, with and without DM, and presence of DM. In the subgroup analysis for the patients with PI ( $\mathrm{n}=1,046)$, median OS and 12-month OS rates were 7.5 months and $35.2 \%$, respectively, in the LRT group and 3.7 months and $14.8 \%$, respectively, in the sorafenib group $(P<0.001$; Figure 2B). Furthermore, other three subgroup analyses for patients with LNM ( $\mathrm{n}=366)$, without DM ( $n=913)$, and with DM $(n=574)$ showed that LRT group had increased OS at 12 months compared to sorafenib group (33.9\% vs $3.9 \%$, Figure $2 \mathrm{C} ; 40.6 \%$ vs $20.5 \%$, Figure 2D; 
A

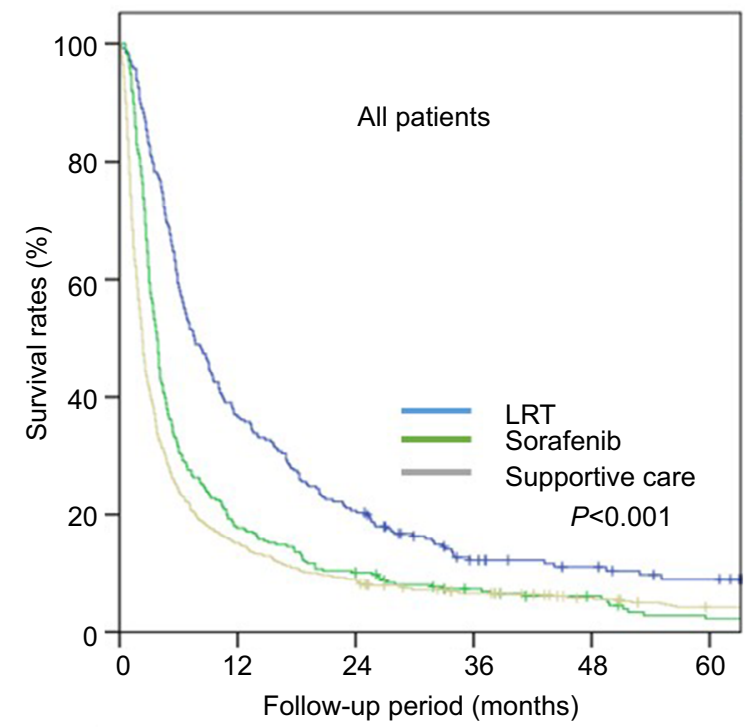

C
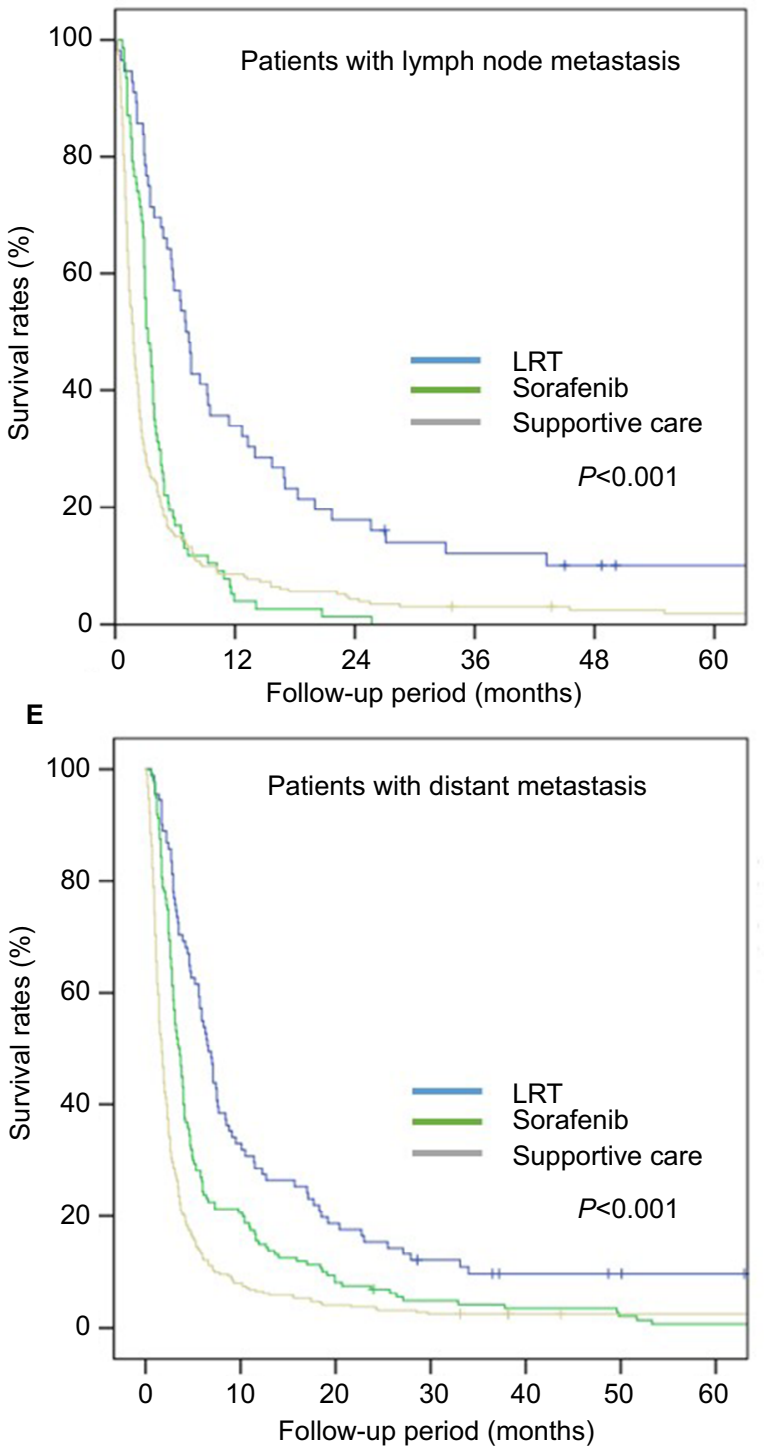

B

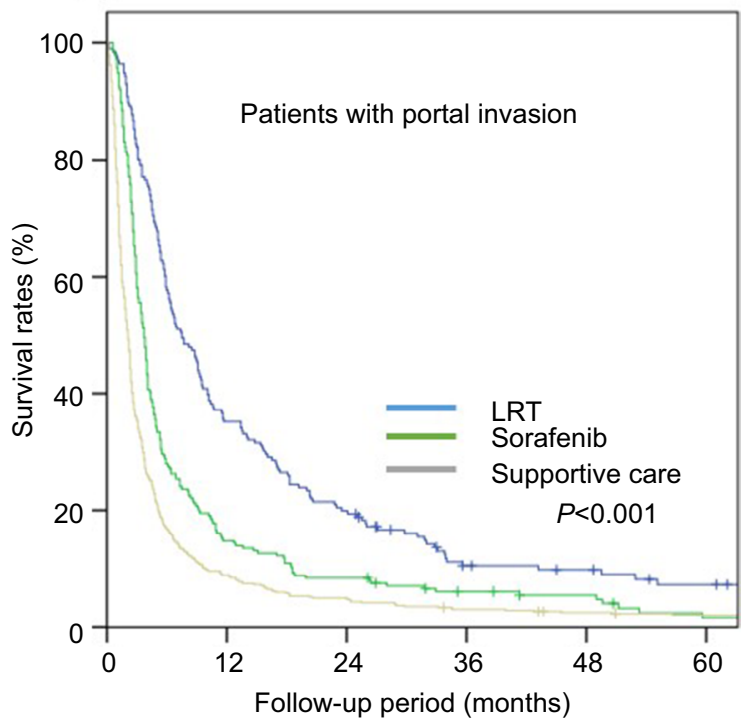

D

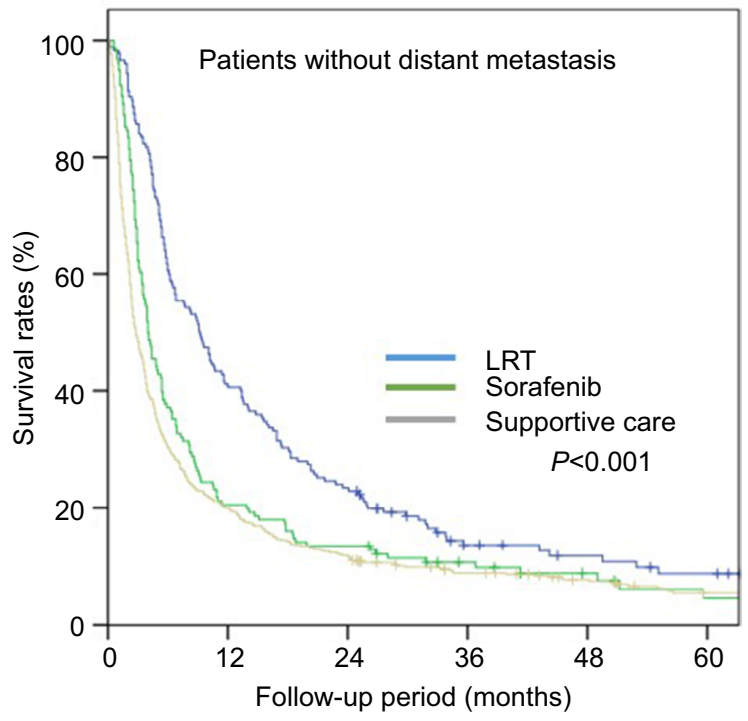

Figure 2 Overall survival according to treatment groups for all patients (A) and each subgroup of patients with portal invasion (B), lymph node metastasis (C), without distant metastasis (D), and with distant metastasis (E). Abbreviation: LRT, locoregional treatment. 
Table 2 Univariate analyses related to survival according to treatment groups for all patients and subgroups of patients by various factors

\begin{tabular}{|c|c|c|c|c|c|c|}
\hline \multirow[t]{2}{*}{ Variables } & \multirow[t]{2}{*}{ LRT } & \multirow[t]{2}{*}{ Sorafenib } & \multirow[t]{2}{*}{ No treatment } & \multicolumn{3}{|l|}{$P$-value } \\
\hline & & & & All groups & RT vs sorafenib & $\begin{array}{l}\text { Sorafenib vs no } \\
\text { treatment }\end{array}$ \\
\hline \multicolumn{7}{|l|}{ All patients $(N=I, 486)$} \\
\hline Number of patients available & 266 & 316 & 904 & & & \\
\hline Median OS $(95 \% \mathrm{Cl})$, months & $7.6(6.1-9.1)$ & $3.8(3.5-4.1)$ & $2.3(2.1-2.5)$ & & & \\
\hline I2-month OS (SE), \% & $36.5( \pm 3.0)$ & $17.7( \pm 2.1)$ & $15.2( \pm \mid .2)$ & $<0.001$ & $<0.001$ & $<0.001$ \\
\hline \multicolumn{7}{|l|}{ Subgroup of patients } \\
\hline \multicolumn{7}{|l|}{ With PI $(n=I, 046)$} \\
\hline Number of patients & 196 & 236 & 613 & & & \\
\hline Median OS $(95 \% \mathrm{Cl})$, months & $7.5(5.8-9.2)$ & $3.7(3.3-4.1)$ & $2.1(1.9-2.3)$ & & & \\
\hline I2-month OS (SE), \% & $35.2( \pm 3.4)$ & $14.8( \pm 2.3)$ & $9.0( \pm 1.2)$ & $<0.001$ & $<0.001$ & $<0.001$ \\
\hline \multicolumn{7}{|l|}{ With LNM (n=366) } \\
\hline Number of patients & 56 & 77 & 233 & & & \\
\hline Median OS $(95 \% \mathrm{Cl})$, months & $7.1(5.9-8.3)$ & $3.3(2.7-3.9)$ & I.8 (I.5-2.I) & & & \\
\hline I2-month OS (SE), \% & $33.9( \pm 6.3)$ & $3.9( \pm 2.2)$ & $8.6( \pm 1.8)$ & $<0.00$ I & $<0.001$ & 0.037 \\
\hline \multicolumn{7}{|l|}{ Without DM $(n=9 \mid 3)$} \\
\hline Number of patients & 175 & 156 & 581 & & & \\
\hline Median OS $(95 \% \mathrm{Cl})$, months & $9.2(6.7-11.7)$ & $4.0(3.2-4.8)$ & $2.8(2.4-3.2)$ & & & \\
\hline I2-month OS (SE), \% & $40.6( \pm 3.7)$ & $20.5( \pm 3.2)$ & $20.0( \pm I .7)$ & $<0.001$ & $<0.001$ & 0.044 \\
\hline \multicolumn{7}{|l|}{ With DM $(n=574)$} \\
\hline Number of patients & 91 & 160 & 323 & & & \\
\hline Median OS $(95 \% \mathrm{Cl})$, months & $6.6(5.5-7.7)$ & $3.5(3.0-4.0)$ & $1.7(1.5-1.9)$ & & & \\
\hline I2-month OS (SE), \% & $28.6( \pm 4.7)$ & $15.0( \pm 2.8)$ & $6.5( \pm I .4)$ & $<0.001$ & $<0.001$ & $<0.001$ \\
\hline
\end{tabular}

Abbreviations: DM, distant metastasis; LN, lymph node; LNM, lymph node metastasis; LRT, locoregional treatment; OS, overall survival; PI, portal invasion; RT, radiation therapy; SE, standard error.

and $28.6 \%$ vs $15.0 \%$, Figure $2 \mathrm{E}$, respectively; $P<0.001$ in all; Table 2). No treatment group showed the worst 12-month OS of $15.2 \%$ in all patients and also in the four subgroups of patients with PI (9.0\%), with LNM (8.6\%), without DM (20.0\%), and with DM (6.5\%).

In multivariable analysis, sorafenib group showed significantly higher risk related to mortality LRT group, not only among all patients (HR: $1.50,95 \%$ CI: $1.23-1.84$, $P<0.001)$, but also between subgroup cohorts with PI (1.55, 95\% CI: $1.23-1.96, P<0.001)$, with LNM (2.42, 95\% CI: 1.53-3.83, $P<0.001)$, without DM (1.43, 95\% CI: 1.10 1.87, $P=0.009)$, and with DM (1.57, 95\% CI: $1.13-2.19$, $P=0.007)$. Further, no treatment group showed the lowest OS compared to other groups, not only among all patients, but also in each subgroup of patients with LNM, without DM, and with $\mathrm{DM}(P<0.001$ in all; Table 3$)$. Among all BCLC C patients, gender $(P=0.002)$, performance status $(P=0.005)$, tumor size $(P<0.001)$, PI $(P<0.001)$, lymph node $(P<0.001)$ and distant metastases $(P<0.001)$, and Child-Pugh score $(P<0.001)$ were statistically significant, but not the age and viral profiles of hepatitis B and C. Multivariable analyses related to OS according to treatment groups for all patients and patients in subgroups by various factors are summarized in Table 3.

\section{Discussion}

Current nationwide cohort analysis of HCC patients of BCLC $\mathrm{C}$ showed that LRT was associated with a significantly longer OS compared with sorafenib as the initial treatment. This study implicated that LRT might be a significant treatment option in addressing an unmet need in treating advanced HCC patients with heterogeneity. To our knowledge, BCLC C is a heterogeneous population with various advanced features that lead to dismal prognosis. ${ }^{13}$ Although sorafenib, a multityrosine kinase inhibitor, has been approved as a standard systemic therapy for patients with advanced HCC, the survival 
Table 3 Multivariable analysis related to survival for all patients and for subgroups of patients by various factors

\begin{tabular}{|c|c|c|c|c|c|c|c|c|c|c|}
\hline \multirow[t]{2}{*}{ Variables } & \multicolumn{2}{|l|}{ All patients } & \multicolumn{2}{|l|}{ With PI } & \multicolumn{2}{|l|}{ With LNM } & \multicolumn{2}{|c|}{ Without DM } & \multicolumn{2}{|l|}{ With DM } \\
\hline & $\begin{array}{l}\operatorname{Exp}(\mathrm{B}) \\
(95 \% \mathrm{Cl})\end{array}$ & $P$-value & $\begin{array}{l}\operatorname{Exp}(\mathrm{B}) \\
(95 \% \mathrm{Cl})\end{array}$ & $P$-value & $\begin{array}{l}\operatorname{Exp}(\mathrm{B}) \\
(95 \% \mathrm{Cl})\end{array}$ & $P$-value & $\begin{array}{l}\operatorname{Exp}(\mathrm{B}) \\
(95 \% \mathrm{Cl})\end{array}$ & $P$-value & $\begin{array}{l}\operatorname{Exp}(\mathrm{B}) \\
(95 \% \mathrm{Cl})\end{array}$ & $P$-value \\
\hline $\mathrm{Age}^{\mathrm{a}}$ & NS & 0.993 & NS & 0.814 & NS & 0.627 & NS & 0.746 & NS & 0.17 \\
\hline \multicolumn{11}{|l|}{ Gender } \\
\hline Female & Reference & & Reference & & Reference & & Reference & & Reference & \\
\hline Male & $\begin{array}{l}1.32 \\
(1.11-1.58)\end{array}$ & 0.002 & $\begin{array}{l}1.27 \\
(1.02-1.59)\end{array}$ & 0.034 & NS & 0.443 & $\begin{array}{l}1.43 \\
(1.15-1.78)\end{array}$ & 0.001 & NS & 0.303 \\
\hline \multicolumn{11}{|l|}{ ECOG PS } \\
\hline 0 & Reference & & Reference & & Reference & & Reference & & Reference & \\
\hline 1 & $\begin{array}{l}1.03 \\
(0.89-1.19)\end{array}$ & 0.686 & $\begin{array}{l}1.14 \\
(0.97-1.35)\end{array}$ & 0.12 & NS & 0.468 & $\begin{array}{l}1.22 \\
(1.02-1.47)\end{array}$ & 0.034 & NS & 0.804 \\
\hline 2 & $\begin{array}{l}1.36 \\
(1.10-1.69)\end{array}$ & 0.005 & $\begin{array}{l}1.68 \\
(1.29-2.19)\end{array}$ & $<0.001$ & NS & 0.025 & $\begin{array}{l}1.79 \\
(1.36-2.36)\end{array}$ & $<0.001$ & NS & 0.715 \\
\hline \multicolumn{11}{|c|}{ Tumor size, cm } \\
\hline$\leq 10$ & Reference & & Reference & & Reference & & Reference & & Reference & \\
\hline$>10$ & $\begin{array}{l}1.49 \\
(1.29-1.71)\end{array}$ & $<0.001$ & $\begin{array}{l}1.35 \\
(1.16-1.59)\end{array}$ & $<0.001$ & NS & 0.124 & $\begin{array}{l}1.58 \\
(1.32-1.88)\end{array}$ & $<0.001$ & $\begin{array}{l}1.32 \\
(1.06-1.65)\end{array}$ & 0.014 \\
\hline \multicolumn{11}{|l|}{ Portal invasion } \\
\hline No & Reference & & \multirow[t]{2}{*}{ NA } & & Reference & & Reference & & Reference & \\
\hline Yes & $\begin{array}{l}1.80 \\
(1.54-2.11)\end{array}$ & $<0.001$ & & & $\begin{array}{l}1.37 \\
(1.01-1.85)\end{array}$ & 0.041 & $\begin{array}{l}2.47 \\
(1.99-3.07)\end{array}$ & $<0.001$ & $\begin{array}{l}1.30 \\
(1.02-1.65)\end{array}$ & 0.036 \\
\hline \multicolumn{11}{|l|}{ LN metastasis } \\
\hline No & Reference & & Reference & & \multirow[t]{2}{*}{ NA } & & Reference & & Reference & \\
\hline Yes & $\begin{array}{l}1.46 \\
(1.24-1.72)\end{array}$ & $<0.001$ & $\begin{array}{l}1.32 \\
(1.07-1.62)\end{array}$ & 0.008 & & & $\begin{array}{l}2.07 \\
(1.63-2.62)\end{array}$ & $<0.001$ & $\begin{array}{l}1.25 \\
(1.00-1.56)\end{array}$ & 0.052 \\
\hline \multicolumn{11}{|l|}{$\begin{array}{l}\text { Distant } \\
\text { metastasis }\end{array}$} \\
\hline No & Reference & & Reference & & Reference & & \multirow[t]{2}{*}{ NA } & & \multirow[t]{2}{*}{ NA } & \\
\hline Yes & $\begin{array}{l}1.52 \\
(1.31-1.76)\end{array}$ & $<0.001$ & $\begin{array}{l}1.34 \\
(1.12-1.61)\end{array}$ & 0.002 & NS & 0.171 & & & & \\
\hline \multicolumn{11}{|c|}{ Initial treatment } \\
\hline LRT & Reference & & Reference & & Reference & & Reference & & Reference & \\
\hline Sorafenib & $\begin{array}{l}1.50 \\
(1.23-1.84)\end{array}$ & $<0.001$ & $\begin{array}{l}1.55 \\
(1.23-1.96)\end{array}$ & $<0.001$ & $\begin{array}{l}2.42 \\
(1.53-3.83)\end{array}$ & $<0.001$ & $\begin{array}{l}1.43 \\
(1.10-1.87)\end{array}$ & 0.007 & $\begin{array}{l}1.57 \\
(1.13-2.19)\end{array}$ & 0.007 \\
\hline $\begin{array}{l}\text { Supportive } \\
\text { care }\end{array}$ & $\begin{array}{l}2.12 \\
(1.77-2.54)\end{array}$ & $<0.001$ & $\begin{array}{l}2.40 \\
(1.95-2.96)\end{array}$ & $<0.001$ & $\begin{array}{l}3.06 \\
(2.01-4.65)\end{array}$ & $<0.001$ & $\begin{array}{l}1.86 \\
(1.49-2.31)\end{array}$ & $<0.001$ & $\begin{array}{l}2.73 \\
(1.99-3.76)\end{array}$ & $<0.001$ \\
\hline \multicolumn{11}{|l|}{ Hepatitis B } \\
\hline No & Reference & & Reference & & Reference & & Reference & & Reference & \\
\hline Yes & NS & 0.479 & NS & 0.336 & NS & 0.267 & NS & $0.87 I$ & NS & 0.896 \\
\hline \multicolumn{11}{|l|}{ Heptatitis C } \\
\hline No & Reference & & Reference & & Reference & & Reference & & Reference & \\
\hline Yes & NS & 0.375 & NS & 0.309 & $\begin{array}{l}0.56 \\
(0.36-0.86)\end{array}$ & 0.008 & NS & 0.466 & NS & 0.596 \\
\hline CPC score ${ }^{a}$ & $\begin{array}{l}1.30 \\
(1.23-1.36)\end{array}$ & $<0.001$ & $\begin{array}{l}1.31 \\
(1.24-1.39)\end{array}$ & $<0.001$ & $\begin{array}{l}1.45 \\
(1.31-1.61)\end{array}$ & $<0.001$ & $\begin{array}{l}1.30 \\
(1.22-1.39)\end{array}$ & $<0.001$ & $\begin{array}{l}1.33 \\
(1.22-1.44)\end{array}$ & $<0.001$ \\
\hline
\end{tabular}

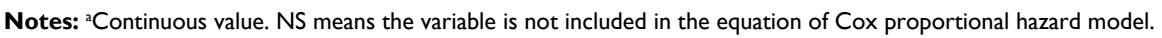

Abbreviations: CPC, Child-Pugh Score; DM, distant metastasis; ECOG PS, Eastern Cooperative Oncology Group performance score; Exp (B), exponential B; LN, lymph node; LNM, lymph node metastatis; LRT, local treatment including RT; NA, not applicable; NS, nonsignificant; PI, portal invasion; RT, radiation therapy. 
gain is modest and the tumor response is unsatisfactory. To overcome the heterogeneity and aggressiveness of such a disease, optimal therapeutic approaches are still required for further investigation. Thus, not only sorafenib, but also various treatment modalities including TACE, external RT, radioembolization, systemic chemotherapy, and combination therapy are being employed based on an empirical consequence. In particular, we found that many previous studies suggested that the incorporation of RT in multimodal approach enhances the survival outcome for patients with BCLC C HCC, ${ }^{14,15}$ and that the utilization of RT has increased for $\mathrm{HCC}$, as the RT technique has remarkably developed, ${ }^{15,16}$ although RT has lower evidence and recommendation level as the first-line treatment modality.

Also, our nationwide study suggested that for some patients with BCLC C $\mathrm{HCC}$ in real practice, sorafenib monotherapy may not be a unique and effective treatment modality. In HCC patients, the prediction of prognosis is complicated not only by the disease stages with heterogeneity, but also by the aspects of cirrhosis and underlying liver function with diversity affecting survival. Therefore, even well-designed trials could not include the various clinical situations due to these multiple factors, which contributed to the inconsistency of therapeutic efficacy between the controlled clinical trial and the community clinical setting. ${ }^{17}$ Importantly, although randomization is the only reliable method to control for confounding factors when comparing treatment groups, it was noted that randomized trials have limitations that they involve only selected patients who are treated according to trial protocols that might not represent real-world practice. ${ }^{2,18,19}$ Notably, in both the SHARP trial and the Asia-Pacific trial with $\sim 50 \%-70 \%$ of patients with extrahepatic spread, ${ }^{6,7}$ we observed that the survival benefits of sorafenib were not significant. Furthermore, the sorafenib group did not have improvement of OS in $35 \%$ of patients with macrovascular involvement in the Asia-Pacific trial. ${ }^{7}$ In other words, other therapy or combination therapies could be more effective than sorafenib alone for some patients with BCLC C HCC who met specific criteria from the protocol criteria of randomized trials.

Thus, many previous studies reported the result of other treatments compared with sorafenib monotherapy for advanced HCC. ${ }^{20-23}$ Among these, Choi et al reported that combination therapy including sorafenib and TACE resulted in a better OS compared with sorafenib monotherapy (8.9 vs 5.9 months, $P=0.009$ ) in patients with BCLC C HCC using propensity score-based methods. ${ }^{20}$ Nakazawa et al reported two times longer median OS in the RT group when they compared survival following sorafenib in patients with unresectable HCC with portal vein tumor thrombosis (PVT) by propensity score matching analysis (10.9 vs 4.8 months; $P=0.025) .{ }^{22}$ In agreement with this viewpoint, our nationwide cohort study, which had the strength of a large-scale allcomers in a clinical setting, ${ }^{18}$ showed consistent results for the therapeutic superiority of LRT compared with sorafenib for HCC BCLC C disease.

This study revealed a significant effect of LRT in all subgroups with adverse features such as patients with PI, with LNM, and with/without DM compared to sorafenib. Among these, especially PI including PVT occurred in most advanced HCC patients and was associated with poor prognosis because of increased risk of tumor spread, elevated portal venous pressure, and decreased portal flow resulting in ascites, jaundice, hepatic encephalopathy, and liver failure. ${ }^{24,25}$ In our study, we observed that $68 \%$ of all patients had PI, and LRT contributed to improvement of OS in the subgroup of patients with PI, compared to sorafenib. Nakazawa et al demonstrated that RT was more effective than sorafenib, because PVT which is intensively irradiated by RT might result in recanalization of the portal vein. Furthermore, other previous studies reported good treatment responses and promising outcomes using RT for PVT. ${ }^{26,27}$ In its extension, in a recent randomized clinical trial, it was worthwhile to show that the efficacy and safety of RT with TACE was superior to those of sorafenib for HCC BCLC C with vascular invasion. ${ }^{9}$ Hence, it is suggested that the presence of PVT in advanced HCC may be one of the indicators for administration of initial LRT. In the future, LRT should be integrated into comprehensive treatment guidelines for advanced HCC with vascular involvement including PVT.

In subgroup analyses, the benefit of LRT as compared to sorafenib was most prominent for the patients with LNM (HR: 2.42, 95\% CI: 1.53-3.83). Although the incidence is rare, LNM of HCC is known to have poor prognosis as DMs. ${ }^{28}$ LNMs can cause serious side effects such as obstructive jaundice, pyloric obstruction, and inferior vena cava obstruction. ${ }^{29}$ Wee et $\mathrm{al}^{30}$ reported that symptoms due to LNM might triple the risk of death in HCC patients. In the recent meta-analysis of studies regarding $\mathrm{RT}$ for $\mathrm{HCC}$ with LNM, the response rate was $73.1 \%$, and it was $82.2 \%$ in the high-dose RT subgroup. ${ }^{31}$ The present study reinforces the utility of RT for HCC with LNM, in addition to the results of previous studies.

Although the strength of this study was the use of a nationwide population-based cohort analysis, there are several limitations. First, our retrospective cohort study has potential 
biases related to unmeasured or unknown confounding variables. Despite our scrupulous study design and control for confounding factors throughout multivariable analyses, these biases might have affected our results. The KCCR does not provide detailed information on the patient's lifestyle or health-related factors, such as smoking history, alcohol consumption, body mass index, and socioeconomic status, which can increase the risk of cancer and were potential confounders. Another limitation is that we were unable to evaluate the complete use of RT or sorafenib. NCCR provided information only regarding whether RT or sorafenib was administered or not. In particular, the therapeutic effect and toxicity of RT are greatly affected by the radiation dose, and the advanced technique is known to have the potential to reduce this effect. ${ }^{32,33}$ As the use of RT in HCC has not yet been accepted as a standard option, details of dose or RT methods are not available in the data source of this study. We do hope that the future data can include the treatment details of RT, so that further analysis is available to optimize application of RT for HCC. Additionally, the "no treatment" subgroup refers to patients who decided to undergo no treatment at first visit, and some of these might visit another hospital to gather second opinion to take any treatment.

Besides the limitations in the study design, our study did not reflect the effects of regorafenib or carbozantinib, which have been shown to improve survival as secondary treatments after sorafenib in a very recent trial. ${ }^{34,35}$ However, our study is about initial treatment, and the role of systemic treatment, including sorafenib and second-line drugs, is more crucial after LRT. The development of new systemic agents is an epoch-making event in the treatment of HCCs, and we hope that the combination of appropriate LRT with new systemic agents will greatly improve the treatment efficiency of advanced HCCs in the future.

Our study has the advantage of demonstrating realworld clinical practice for BCLC C patients in the Republic of Korea. In addition, with the large number of patients, sufficient statistical power could be achieved on analyzing various clinical situations of BCLC C. The study by Yoon et $\mathrm{al}^{9}$ was the first randomized study to demonstrate the survival benefit of LRT as an initial option in BCLC $\mathrm{C}$ patients, but the limitations were that each arm had as small as 45 patients and covered only patients with vascular invasions. The present study is able to claim the benefit of LRT in all BCLC C patients complementary to the study by Yoon et al. ${ }^{9}$

In conclusion, our nationwide population study showed that LRT as an initial treatment showed survival benefit as compared to sorafenib in BCLC C patients. In practice, owing to moderate efficacy of sorafenib, in recent years, local treatment modalities including RT for HCC BCLC C stage have continued to be investigated in comparison with sorafenib monotherapy to overcome heterogeneous disease entity and its prognosis. Accordingly, future prospective, randomized, and controlled studies are warranted to compare the effectiveness of diverse treatment modalities including RT and to incorporate them into a multidisciplinary treatment approach in conjunction with sorafenib.

\section{Acknowledgments}

This study was supported by the National Research Fund of Korea (NRF-2018R1D1A1B07046998). The clinical data of the present study were provided by the Korean Central Cancer Registry of National Cancer Center, Ministry of Health and Welfare, Republic of Korea.

\section{Disclosure}

The authors report no conflicts of interest in this work.

\section{References}

1. El-Serag HB, Rudolph KL. Hepatocellular carcinoma: epidemiology and molecular carcinogenesis. Gastroenterology. 2007;132(7): 2557-2576.

2. Han K, Kim JH, Ko GY, Gwon DI, Sung KB. Treatment of hepatocellular carcinoma with portal venous tumor thrombosis: a comprehensive review. World J Gastroenterol. 2016;22(1):407-416.

3. Llovet JM, Brú C, Bruix J. Prognosis of hepatocellular carcinoma: the BCLC staging classification. Semin Liver Dis. 1999;19(3):329-338.

4. Forner A, Reig ME, Rodriguez de Lope C, Bruix J, de Lope CR. Current strategy for staging and treatment: the BCLC update and future prospects. Semin Liver Dis. 2010;30(01):61-74.

5. Nanashima A, Tobinaga S, Kunizaki M, et al. Strategy of treatment for hepatocellular carcinomas with vascular infiltration in patients undergoing hepatectomy. J Surg Oncol. 2010;101(7):557-563.

6. Llovet JM, Ricci S, Mazzaferro V, et al. Sorafenib in advanced hepatocellular carcinoma. N Engl J Med. 2008;359(4):378-390.

7. Cheng AL, Kang YK, Chen Z, et al. Efficacy and safety of sorafenib in patients in the Asia-Pacific region with advanced hepatocellular carcinoma: a Phase III randomised, double-blind, placebo-controlled trial. Lancet Oncol. 2009;10(1):25-34.

8. Rim $\mathrm{CH}$, Yoon WS. Leaflet manual of external beam radiation therapy for hepatocellular carcinoma: a review of the indications, evidences, and clinical trials. Onco Targets Ther. 2018;11:2865-2874.

9. Yoon SM, Ryoo BY, Lee SJ, et al. Efficacy and safety of transarterial chemoembolization plus external beam radiotherapy vs sorafenib in hepatocellular carcinoma with macroscopic vascular invasion: a randomized clinical trial. JAMA Oncol. 2018;4(5):661-669.

10. National Cancer Information Center of Korea. Available from: https:// www.cancer.go.kr/lay1/S1T639C641/contents.do. Accessed September 7, 2018.

11. Seo YS, Kim MS, Kang JK, et al. The clinical utilization of radiation therapy in Korea between 2011 and 2015. Cancer Res Treat. 2018;50(2):345-355.

12. European Association for the Study of the Liver. EASL clinical practice guidelines: management of hepatocellular carcinoma. $J$ Hepatol. 2018;69(1):182-236.

13. Bruix J, Sherman M; American Association for the Study of Liver Diseases. Management of hepatocellular carcinoma: an update. Hepatology. 2011;53:1020-1022. 
14. Hawkins MA, Dawson LA. Radiation therapy for hepatocellular carcinoma: from palliation to cure. Cancer. 2006;106(8):1653-1663.

15. Rim CH, Kim CY, Yang DS, Yoon WS. Comparison of radiation therapy modalities for hepatocellular carcinoma with portal vein thrombosis: a meta-analysis and systematic review. Radiother Oncol. 2018;129(1):112-122.

16. Rim CH, Seong J. Application of radiotherapy for hepatocellular carcinoma in current clinical practice guidelines. Radiat Oncol J. 2016;34(3):160-167.

17. Nault JC. The end of almost 10 years of negative RCTs in advanced hepatocellular carcinoma. Lancet. 2017;389(10064):4-6.

18. James S, Rao SV, Granger CB. Registry-based randomized clinical trials - a new clinical trial paradigm. Nat Rev Cardiol. 2015;12(5):312-316.

19. Chalkidou K, Tunis S, Whicher D, Fowler R, Zwarenstein M. The role for pragmatic randomized controlled trials (pRCTs) in comparative effectiveness research. Clin Trials. 2012;9(4):436-446.

20. Choi GH, Shim JH, Kim MJ, et al. Sorafenib alone versus sorafenib combined with transarterial chemoembolization for advanced-stage hepatocellular carcinoma: results of propensity score analyses. Radiology. 2013;269(2):603-611.

21. Wu FX, Chen J, Bai T, et al. The safety and efficacy of transarterial chemoembolization combined with sorafenib and sorafenib monotherapy in patients with BCLC stage $\mathrm{B} / \mathrm{C}$ hepatocellular carcinoma. BMC Cancer. 2017;17(1):645.

22. Nakazawa T, Hidaka H, Shibuya A, et al. Overall survival in response to sorafenib versus radiotherapy in unresectable hepatocellular carcinoma with major portal vein tumor thrombosis: propensity score analysis. BMC Gastroenterol. 2014;14(1):84.

23. Tanaka Y, Nakazawa T, Komori S, et al. Radiotherapy for patients with unresectable advanced hepatocellular carcinoma with invasion to intrahepatic large vessels: efficacy and outcomes. $J$ Gastroenterol Hepatol. 2014;29(2):352-357.

24. Minagawa M, Makuuchi M. Treatment of hepatocellular carcinoma accompanied by portal vein tumor thrombus. World J Gastroenterol. 2006;12(47):7561-7567.

25. Liu L, Zhao Y, Qi X, et al. Transjugular intrahepatic portosystemic shunt for symptomatic portal hypertension in hepatocellular carcinoma with portal vein tumor thrombosis. Hepatol Res. 2014;44(6):621-630.
26. Huang YJ, Hsu HC, Wang CY, et al. The treatment responses in cases of radiation therapy to portal vein thrombosis in advanced hepatocellular carcinoma. Int J Radiat Oncol Biol Phys. 2009;73(4):1155-1163.

27. Kim DY, Park W, Lim DH, et al. Three-dimensional conformal radiotherapy for portal vein thrombosis of hepatocellular carcinoma. Cancer. 2005;103(11):2419-2426.

28. Hasegawa K, Makuuchi M, Kokudo N, et al. Impact of histologically confirmed lymph node metastases on patient survival after surgical resection for hepatocellular carcinoma: report of a Japanese nationwide survey. Ann Surg. 2014;259(1):166-170.

29. Zeng ZC, Tang ZY, Fan J, et al. Consideration of role of radiotherapy for lymph node metastases in patients with HCC: retrospective analysis for prognostic factors from 125 patients. Int J Radiat Oncol Biol Phys. 2005;63(4):1067-1076.

30. Wee CW, Kim K, Chie EK, Yu SJ, Kim YJ, Yoon JH. Prognostic stratification and nomogram for survival prediction in hepatocellular carcinoma patients treated with radiotherapy for lymph node metastasis. Br J Radiol. 2016;89(1065):20160383.

31. Rim CH, Kim CY, Yang DS, Yoon WS. The role of external beam radiotherapy for hepatocellular carcinoma patients with lymph node metastasis: a meta-analysis of observational studies. Cancer Manag Res. 2018;10:3305-3315.

32. Rim CH, Kim CY, Yang DS. Comparison of radiation therapy modalities for hepatocellular carcinoma with portal vein thrombosis: a metaanalysis and systematic review. Radiother Oncol.2018;129(1):112-122.

33. Hou JZ, Zeng ZC, Wang BL, Yang P, Zhang JY, Mo HF. High dose radiotherapy with image-guided hypo-IMRT for hepatocellular carcinoma with portal vein and/or inferior vena cava tumor thrombi is more feasible and efficacious than conventional 3D-CRT. Jpn J Clin Oncol. 2016;46(4):357-362.

34. Abou-Alfa GK, Meyer T, Cheng AL, et al. Cabozantinib (C) versus placebo (P) in patients (PTS) with advanced hepatocellular carcinoma (HCC) who have received prior sorafenib: results from the randomized Phase III CELESTIAL trial. J Clin Oncol. 2018;36(4 Suppl):207.

35. Bruix J, Qin S, Merle P, et al. Regorafenib for patients with hepatocellular carcinoma who progressed on sorafenib treatment (RESORCE): a randomised, double-blind, placebo-controlled, Phase 3 trial. Lancet. 2017;389(10064):56-66.
Cancer Management and Research

\section{Publish your work in this journal}

Cancer Management and Research is an international, peer-reviewed open access journal focusing on cancer research and the optimal use of preventative and integrated treatment interventions to achieve improved outcomes, enhanced survival and quality of life for the cancer patient. The manuscript management system is completely online and includes

\section{Dovepress}

a very quick and fair peer-review system, which is all easy to use. Visit http://www.dovepress.com/testimonials.php to read real quotes from published authors. 